\title{
Influence of a university teacher virtual image on the students' morality character
}

\author{
G.M. Burakanova ${ }^{1 *}$, A.A. Maimakova ${ }^{2}$, and S.S. Tsaregorodtseva ${ }^{3}$ \\ ${ }^{1}$ L.N. Gumilyov Eurasian National University, Nur-Sultan, Kazakhstan \\ ${ }^{2}$ L.N. Gumilyov Eurasian National University, Nur-Sultan, Kazakhstan \\ ${ }^{3}$ V.I. Vernadsky Crimean Federal University, Simferopol, Russia
}

\begin{abstract}
The ability to form a positive image of a university teacher is one of the most significant aspect for increasing the prestige and influence of this profession. The relevance of the topic depends on the situation that arose against the background of the COVID-19 pandemic and the forced move to remote learning. The authors of the article analyzed the studies of Kazakhstani and foreign experts on the image phenomenon. There is given a definition of the essential content of the "image" concept. There have been determined the criteria for matching the categories of components that make up the image. There have been identified the functions of the teacher's image in education. There are determined main characteristics of a university teacher's image. A number of technologies for formation of a positive image of a teacher are described. The article presents the results of a study conducted among students of a Kazakhstani higher educational institution. The research identified the main image-forming qualities of a modern teacher and their impact on the educational process. The authors propose own technology for creating a positive image of a university teacher based on the results of the study and studied theoretical foundation.
\end{abstract}

\section{A problem statement}

The issue of the formation of a positive image of a university teacher in the era of the information society development is especially acute. Advanced development of the Internet, social media, blogs, mobile apps and etc. leads to the fact that a modern teacher is no longer an exclusive carrier of information and its only source.

The COVID-19 pandemic and the quarantine caused by it required the measures to reduce the risks of infecting with coronavirus in all spheres of activity. In education such measure was an urgent moving of the educational process to an online format using information and communication technologies [1]. Teachers are forced to actively study and master the Internet resources of Microsoft Teams, Zoom and etc. The newest interactive technologies of the future have entered everyday reality and have become a part of it.

Digitalization and transformation of the educational environment into the service sector require from the university teacher a systems thinking, multilingualism and

\footnotetext{
*Corresponding author: galiyab@mail.ru
} 
multiculturalism, creativity, the ability to focus on the student as the main consumer of educational services, as well to manage projects and work under conditions of uncertainty. Among other things, the teacher should have soft skills and hard-skills indicating its effectiveness.

Undoubtedly, these aspects have become a new challenge for higher education teachers and called them for willingness to demonstrate new competencies and skills in their activities. The process of forming a holistic professional image of the teacher is of paramount importance, since it is an attribute of professional and social relations influencing the perception of the teacher by society.

\subsection{The objective of the work}

The information society makes new communicative and moral requirements for the image of the university teacher: on the one hand, to achieve recognition and understanding from the student audience, and on the other, to preserve and convey the high standard of moral culture that distinguishes a teacher from representatives of other professions.

The relevance of the issue, among other things, is in the fact that a lot of studies have been devoted to the study of the concept of a pedagogical image, various manifestations of the image characteristics of secondary school teachers personality, while there are not many works devoted to the specifics of the university teacher image, study of characteristics that determine their image as positive, negative or neutral. The virtual image of university teachers is considered indirectly, through personal pages in social networks or use of information and communication technologies in their activities.

As a result, the modern image of university teacher is their contribution to the formation of a qualitatively new educational and digital environment. A study conducted among students of higher education helped us to determine the set and importance of imageforming characteristics that a modern teacher should have. Having studied a wide range of theoretical sources devoted to the phenomenon of image and based on the results of our own research, we have developed a technology for the formation of a virtual positive image of a university teacher.

\section{Results of the research}

Professional image is understood as the image of an individual determined by their professional qualities. Researchers L.K. Averchenko, G.M. Zalesov, R.I. Mokshantsev, V.M. Nikolaenko [2] consider these qualities to be professional competence, moral reliability, humanitarian erudition (knowledge in the field of world culture, universal values, etc.), communicative attractiveness, as well as the use of psychologic techniques.

In a broad sense the image phenomenon and its manifestation were studied by $\mathrm{V}$. Shepel, G. Pocheptsov, A. Markova, L. Donskaya and etc. As a separate sphere, pedagogical imageology was studied by A. Kalyuzhny, V. Kan-Kalik, E. Passov, V. Cherepanova, E. Yamburg and etc. In their studies authors focus more on the external manifestations of the teacher's personality than on their individual teaching style.

The concept of "image" means the impression that a person makes in society; it is a set of external and internal personal qualities. The domestic researcher A. Kalyuzhny defines the image as a complex idea of a person which is formed as a result of the impressions received from the appearance, behavior, mentality and other factors [3]. At the same time, the Russian imageologist V. Cherepanova believes that "an individual image is a purposefully formed integral, holistic and dynamic phenomenon, provided by the correspondence and convergence of the internal and external individual, personal and soft 
competencies of the subject to ensure the harmonious interaction of the subject with nature, society and itself "[4].

Foreign researchers N. Bennet, J. Heimlich, E. Norland, C. Campbell, H. Kryszewska, A. Grasha, D. Brown consider the image as a teaching style [5-9]. According to these researchers, each teacher has a certain set of qualities that make their image unique. $P$. Eggen, D. Kuachak, P. Lightbown, N. Spada, H. Guangwei say that the image of the teacher is an important factor determining learning outcomes [10-12]. H. Puchta, M. Rinvolucri believe that the teacher can correct the qualities that make it difficult to interact with students through the analysis of their own image [13].

Studying the components that form the image of the teacher, researchers distinguish them into separate categories. For example, A. Kalyuzhny considering the structure of the university teacher's image describes four groups of characteristics: external appearance, verbal and non-verbal means of communication, internal conformity of the profession's image or inner self [3]. V. Shepel distinguishes three categories of personal qualities. The first group is formed by qualities that make people like them: sociability, empathy, eloquence, reflexiveness. The second group includes those qualities that indicate a high level of education and upbringing of the individual: moral values, mental health, mastery of interpersonal communication and conflict prevention technologies. The third category is made up of characteristics that indicate personal and professional experience [14].

Boyko V. noting the complexity of the image structure suggests to consider the image as a unity which includes the following components:

1) audio-visual culture of the individual - how literate and pleasant speech is, what's the manner, what and how a person is dressed, what's their hairstyle and etc.;

2) personal style - in other words, different aspects of personality behavior: professional, intellectual, emotional, moral, communicative, ethical, aesthetic;

3) inner philosophy and value system of the individual - what they think about life, about work involved, about the people with whom they deal, what are their moral principles;

4) attributes that emphasize the status and aspirations of the individual - office furniture, car, pets and etc.;

5) psycho-hygienic self-concept - an attractive psycho-hygienic image of a partner, i.e. a person is externally and internally calm, active, in a good mood, benevolent, optimistic, peaceful [15].

According to imageologists, the breadth of the image use determines its focus on performing different functions. For example, I. Simonova studying the issues of forming the image of higher education subjects claims that in the most general sense the image performs an axiological function that involves a value exchange between the communication parties. Specific social and normative representations, as well as appearance and behavior in the process of communication are controlled by the regulatory function. The function of self-presentation is responsible for creating an image, while the function of organizing attention will help to highlight precisely those qualities of a person that will impress the people around them and remain in their minds. The fixation of the created image in the public consciousness through the selection of the most prominent qualities of the subject is carried out by the function of attracting and organizing attention. Also, the image performs an adaptive function that provides a comparison of the personal expectations of the subject of communication with corporate requirements. The psychological function is responsible for the creation of psychological comfort during interaction with people around and the growth of a sense of agency. The function of socialsymbolic recognition ensures the readiness of the individual for interaction in society, the determination of communicative partners and personal identity. The communicative function of the image is aimed at the exchange of information between the communication 
parties, and the personality-uplifting function gives the subject a sense of success, significance, demand, stimulates the desire of others to imitate him [16].

Kazakhstani researchers A. Mynbayeva and A. Zhamankulova distinguish other functions of a pedagogical image:

- social and informational function - informing society and public about the personality of the teacher or educational organization;

- educative function - leading of the young generation by personal example of the teacher;

- professional function - a positive pedagogical image contributes to the development of the profession and improvement of professional personnel training, creation of a positive image of the profession in the society;

- motivational function - motivates the teacher to self-development and self-realization which provide them with material wealth and decent working conditions;

- developmental function - directly contributes to the development and self-realization of the individual; development of self-esteem, reflection; formation of their new competencies, improvement of the pedagogical skill of the teacher, receiving new achievements and awards [17].

Thus, our analysis of Kazakhstani and foreign imageologists' works aimed at defining the essential content of the "image" concept, identifying criteria for matching a particular category of image components, defining the image functions in an educational environment allows us to formulate the characteristics that form the image of a higher school teacher.

The external components of the teacher's image mean such externals as maintaining a certain (business) style of dressing, verbal and non-verbal characteristics of interaction, and the arrangement of the space around themselves. In other words, this is the picture that arises in consciousness when we see and perceive the teacher, as well as the image that is imprinted in our memory after interacting with the teacher. Externals are teacher's facial expressions, walk, manner, gestures, clothe, hairstyle and etc.

The internal components of the teacher's image are personal qualities, values, worldview, intercultural and interpersonal sensitivity and empathy, attitudes towards dialogue and understanding, multilingualism, multiculturalism, soft and hard skills. The category of internal components also includes the teacher's erudition, their interests, hobbies and creativity.

Volitional powers, temperament, emotions of the teacher are the procedural aspect of the image while their value aspect is the life position of a person, their value attitudes and priorities. The professional aspect of the image includes the theoretical and practical experience of the teacher, author's methods, publications, feedback from students and colleagues about their professional competence, as well as evidence of their professional achievements (awards, prizes).

The integrity of the teacher's image in which their externals correspond to internal attitudes, their character and views is extremely important. The image of a higher school teacher can be perceived by society as positive, negative and neutral [18].

The term "positive" means that the appearance that the teacher takes has socially acceptable qualities in public opinion. A positive image is important for the teacher since it is projected on the systematism of moral attitudes and values among students.

Negative image reflects the socially negative characteristics of the teacher's image, respectively. It means inadequate, incorrect, false reflection of the external and internal image of the teacher in the public consciousness. According to Vardanyan M., a negative image of the teacher affects students depressingly, provokes their rapid fatigue, nervous breakdowns and outbursts of aggression [19].

Neutral image is the inexpressiveness of external and internal qualities of the teacher's personality, absence of the qualities in public opinion. Actually, there is no neutral image, 
since the image reflects the qualitative characteristics of a person and is assessed through the opposite categories: "positive - negative", "good - bad". But in our opinion, the term "neutral image" has the right to exist as a concept that haven't yet formed, finished and "become". It can be neutral, implicit but in any case it affects the emotional-sensory layer of personal perception. Having elements of art in its composition, the image is perceived at the sensory level of reflection and must be "liked - disliked", in other words, in the perception of the image "people have different tastes", although objectively the criterion of assessment is the specific historical norms of moral and aesthetic perception [20].

It is clear that depending on the historical era, the prevailing moral and aesthetic ideas, the same qualities of the teacher's personality will be perceived in a different system of assessments.

We carried out a study the purpose of which was to determine the image-forming qualities of a university teacher in modern conditions by students. The respondents were students of Toraighyrov University (note - a state university located in Pavlodar, Republic of Kazakhstan). In total, 100 students of all years took part in our study.

To achieve this goal, the students were given the task of preparing a short essay on Ideal Image of a Teacher in Remote Learning. Further, using the content analysis of the of the essays we identified and ranked the main image-forming characteristics of the teacher's virtual image as follows:

1) for $15.4 \%$ of students in the image of the teacher it is important to be motivated to constantly improve the level of their education development. The teacher whose knowledge is only within the framework of the taught subject becomes uninteresting for students and causes for concern that the quality of their professional training is under threat;

2) $17.5 \%$ of students respect adequate exactingness in the teacher since this quality helps them thoroughly prepare for classes and, therefore, catch on educational material which positively affects the creation of their professional competencies;

3) a healthy sense of humor of the teacher is assessed by $23.2 \%$ of respondents, since it helps to relieve the stress during the educational process, and therefore contributes to the formation of a favorable working atmosphere during the learning process;

4) $31.1 \%$ of students believe that the teacher should be fair, objective and unprejudiced in assessing knowledge regardless of what kind of relationship they have with students at the time of training;

5) $32.3 \%$ of the respondents reckon the communication in the important ideal appearance of the teacher noting that it motivates to study and contributes to the better digestion of the studied material;

6) despite the mostly remote format of learning in the last year, $45.8 \%$ of students consider the teacher's appearance significant, assessing their cleanliness, neatness in clothes, restraint in makeup, ability to look appropriately for the occasion;

7) for $56.3 \%$ of students consider important the professional competence of the teacher, to which they refer a confident knowledge of the material, orotundity, perspicuity, illustrative examples based on their own professional experience;

8) majority of students $(63.6 \%)$ consider the following important qualities of the teacher's personality: benevolence, absence of violent behavior and soreness towards students and colleagues;

9) the transition from traditional education to the online format has led to the fact that $71.4 \%$ of students consider the most important quality of a university teacher is the ability to use information and communication technologies in the learning process, interactive lectures, video presentations, etc.

Thus, the analysis of students' opinions demonstrated the fact that the teacher's image is a factor that determines their attitude to the course and influences the formation of their professional competencies. The results of the study showed that despite remote learning the 
requirements level of youth to the personal and professional characteristics of the teacher remains quite high. In our opinion, taking into account the results of such studies in the educational process of higher education will increase the prestige and authority of the teacher among students, create favorable conditions for interpersonal interaction and, as a result, improve the quality of future specialists training.

Today, there are a number of different image forming technologies that can be used by both beginners and experienced university teachers. These technologies change as they possess such qualities as dynamism and flexibility depending on the surrounding circumstances, educational process subjects, time and other conditions.

According to V. Shepel, creating an image is a consistent implementation of six minitechnologies. These include: 1) confirmation of the starting conditions for mastering the technology; 2) "building" of appearance; 3) "mechanics communication"; 4) "fluidic radiance"; 5) practicing rhetorical techniques; 6) bringing all mini-technologies into a single whole [21].

The technology of creating the image of L. Brown is based on the idea of a vast increased, especially in recent years, the influence of the media. Based on this she suggests when forming the image to take into account such factors as appearance, voice, public speaking, interaction with the press, behavior in front of the TV, maintaining a constant form [22].

Scott D. offering his own technology distinguishes three main stages of creating an image:

- Stage 1 - creation of an imitation sketch of an image that is formed in the imagination on the basis of observations, the study of literary sources, views and judgments of others;

- Stage 2 - formation of a role image, the teacher's practical getting into an imaginary character;

- Stage 3 - creation of a "real life" image corresponding to an imaginary model; alliance of the teacher's personality with the created character which begins to exist as reality.

Despite the fact that this technology concerns the internal image components, in a similar way it is necessary to choose the criteria for the external characteristics of the image in order to bring form and content to the unity. That is, the teacher needs to think over his appearance in order to emphasize both universal human values and professional integrity [22].

Having studied the theoretical approaches to the formation of the structure and content components of the teacher's image, compared and analysed the listed methods of creating a positive image of the teacher, we propose the below technology forming a virtual positive image of a university teacher and taking into account the modern socio-cultural situation in the world. The technology consists of several successive stages:

- Stage 1 - identification of university teacher readiness for implementation of their profession, i.e. assessment of their abilities, personal and professional qualities, life and professional experience, etc.;

- Stage 2 - comparison of the teacher's real appearance with the ideal figure;

- Stage 3 - improvement of such external characteristics of the teacher's image as facial expressions, hairstyles, clothes, makeup, gestures, walk and etc.;

- Stage 4 - improving information and communication skills, including increasing the proficiency in information resources and hardware, mastering oratorical skill, the technique of discussions and negotiations, etc.;

- Stage 5 - practicing behavioral skills, including the cultural behavior, the ability to leave a positive impression of oneself, the skill of solving pedagogical problems, the ability to avoid conflicts or resolve conflict situations, etc.;

- Stage 6 -formation of a healthy lifestyle and the elimination or minimization of bad habits. 


\section{Conclusions}

Thus, formation of a positive image of a teacher in modern socio-cultural conditions is an important measure that contributes to strengthening the reputation, increasing the prestige and authority of higher education in general and, as a consequence, the positive influence of teachers on students not only in the online but also in offline space. Character of the teacher, their virtual image has the power of an educational influence on students as a personal example has the most powerful educational force. The image of the modern university teacher is a complex integrative form in which the external and internal components of the personality are harmoniously combined with the teacher's professional competencies.

\section{References}

1. United Nations Policy Brief: Education during COVID-19 and beyond, access mode: https://unsdg.un.org/sites/default/files/2020-08/sg_policy_brief_covid19_and_education_august_2020.pdf (2020)

2. L.K. Averchenko, G.M. Zalesov, R.I. Mokshantsev, V.M. Nikolaenko, Managerial psychology. ed. M.V. Udaltsov, 149 (1999)

3. A.A. Kalyuzhny, Psychology of the teacher's image formation, 224 (2004)

4. V.N. Cherepanova, Introduction to Pedagogical Imageology, 194 (2006)

5. N. Bennet, Teaching styles and pupil progress, Harvard University Press, 203 (1976)

6. J. Heimlich, E. Norland, Teaching style: Where are we now?, New directions for adult and continuing education, 93, 40-56 (1994)

7. C. Campbell, H. Kryszewska, Towards teaching. Oxford, Heinemann, 86 (1995)

A. Grasha, Teaching with style: a practical guide to enhancing learning by understanding teaching and learning styles, Pittsburgh, Alliance Publishers, 385 (1996)

8. D. Brown, Principles of language learning and teaching, 347 (2007)

9. P. Eggen, D. Kuachak, Strategies for teachers. Teaching content and thinking skills, 346 (1996)

10. P. Lightbown, N. Spada, How Languages are Learned, 252 (1999)

11. H.U. Guangwei, Teaching and Learning a Second Language, Asian Journal of English Language Teaching, 14, 151-156 (2004)

12. H. Puchta, M. Rinvolucri, Multiple intelligences in EFL exercises for secondary and adult students, Hebling languages, 158 (2005)

13. V.M. Shepel, Imageology: secrets of personal charm, Cultura i Sport, Uniti Publ., 320 (1994)

14. L.K. Averchenko, Image and personal growth: study aid. Novosibirsk, 146 (1999)

15. I.F. Somonova, Image forming of social and cultural sphere specialist in the cultural and educational space of the university, 237 (2014)

16. A.K. Mynbayeva, A. Zhamankulova, Image of the teacher and the teacher of the university: a comparative aspect, Bulletin. «Pedagogical science» series, 2(36) (2012)

17. G. Burakanova, A. Akhmetov, Image of the country and public service, 195 (2007)

18. M.R. Vardanyan, Image of a teacher as a factor of health preservation of educational process subjects in primary school, 23 (2007) 
19. G.M. Burakanova, L.I. Izteleyova, Imageology, 171 (2011)

20. V.M. Shepel, Imageology, 407 (2002)

21. I.S. Zheredeva, Methods of forming the image of a university teacher, Spirituality of personality: methodology, theory and practice, 4(73), 48-61 (2016) 